\title{
REVIEW
}

\section{Genome-wide effects of chromatin on vitamin D signaling}

\author{
Andrea Hanel, Henna-Riikka Malmberg and Carsten Carlberg \\ School of Medicine, Institute of Biomedicine, University of Eastern Finland, Kuopio, Finland \\ Correspondence should be addressed to C Carlberg: carsten.carlberg@uef.fi
}

\begin{abstract}
Molecular endocrinology of vitamin $\mathrm{D}$ is based on the activation of the transcription factor vitamin $D$ receptor (VDR) by the vitamin D metabolite $1 \alpha, 25$-dihydroxyvitamin $D_{3}$. This nuclear vitamin D-sensing process causes epigenome-wide effects, such as changes in chromatin accessibility as well as in the contact of VDR and its supporting pioneer factors with thousands of genomic binding sites, referred to as vitamin $D$ response elements. VDR binding enhancer regions loop to transcription start sites of hundreds of vitamin D target genes resulting in changes of their expression. Thus, vitamin $D$ signaling is based on epigenome- and transcriptome-wide shifts in VDR-expressing tissues. Monocytes are the most responsive cell type of the immune system and serve as a paradigm for uncovering the chromatin model of vitamin D signaling. In this review, an alternative approach for selecting vitamin $D$ target genes is presented, which are most relevant for understanding the impact of vitamin D endocrinology on innate immunity. Different scenarios of the regulation of primary upregulated vitamin $\mathrm{D}$ target genes are presented, in which vitamin D-driven super-enhancers comprise a cluster of persistent (constant) and/or inducible (transient) VDR-binding sites. In conclusion, the spatio-temporal VDR binding in the context of chromatin is most critical for the regulation of vitamin $D$ target genes.
\end{abstract}

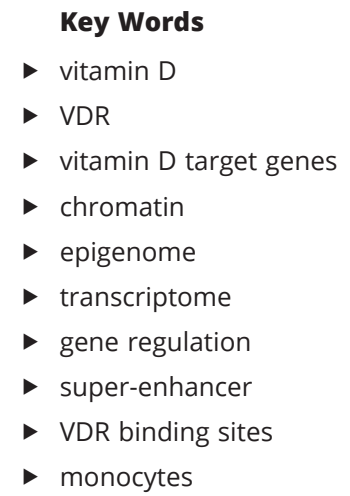

Journal of Molecular Endocrinology (2020) 64, R45-R56

\section{Introduction}

The micronutrient vitamin $\mathrm{D}_{3}$ is known best as a key regulator of calcium homeostasis, which is essential for proper bone formation (van de Peppel \& van Leeuwen 2014, Carmeliet et al. 2015). Interestingly, the nuclear receptor for vitamin D, VDR, evolved some 550 million years ago in a boneless fish, i.e. even before vertebrates developed a stable skeleton for locomotion (Whitfield et al. 2003, Bouillon \& Suda 2014). Thus, in analogy to other members of the nuclear receptor superfamily, VDR's evolutionary oldest function was the control of energy metabolism, supporting the evolving immune system of ancestral vertebrates (Hanel \& Carlberg 2019). Vitamin D supports the immune system in its fight against infections, such as tuberculosis (Chun et al. 2014), and in parallel prevents autoimmune disorders, such as multiple sclerosis (Lu et al. 2019).

Vitamin $\mathrm{D}_{3}$ can be synthesized in human skin via an UV-B-dependent, non-enzymatic reaction that uses the cholesterol precursor 7-dehydrocholesterol as a substrate (Holick 2011). The energy of UV-B opens the B-ring and creates a biologically inert secosteroid. However, hydroxylations first at carbon 25 of the side chain (producing 25-hydroxyvitamin $\mathrm{D}_{3}$ ) and then at carbon 1 within the A-ring create the most active vitamin $\mathrm{D}$ metabolite $1,25(\mathrm{OH})_{2} \mathrm{D}_{3} \quad\left(1 \alpha, 25\right.$-dihydroxyvitamin $\left.\mathrm{D}_{3}\right)$ (Fig. 1A). The molecule easily passes through biological 
membranes and binds with a remarkably high affinity of $0.1 \mathrm{nM}$ to the VDR (Haussler et al. 2013). There are no other cellular proteins that bind vitamin $\mathrm{D}$ and/or its metabolites with comparable affinity. However, the endocytosis receptor megalin in the plasma membrane supports the uptake of vitamin D compounds, in particular in the kidneys (Nykjaer et al. 1999), and the membraneassociated endoplasmatic protein disulfide isomerase PDIA3 has been shown to be affected in its function by vitamin D (Khanal \& Nemere 2007). Nevertheless, neither megalin nor PDIA3 affects the functions of vitamin D on gene expression in the nucleus. Since most human tissues and cell types express the VDR gene (www.proteinatlas.

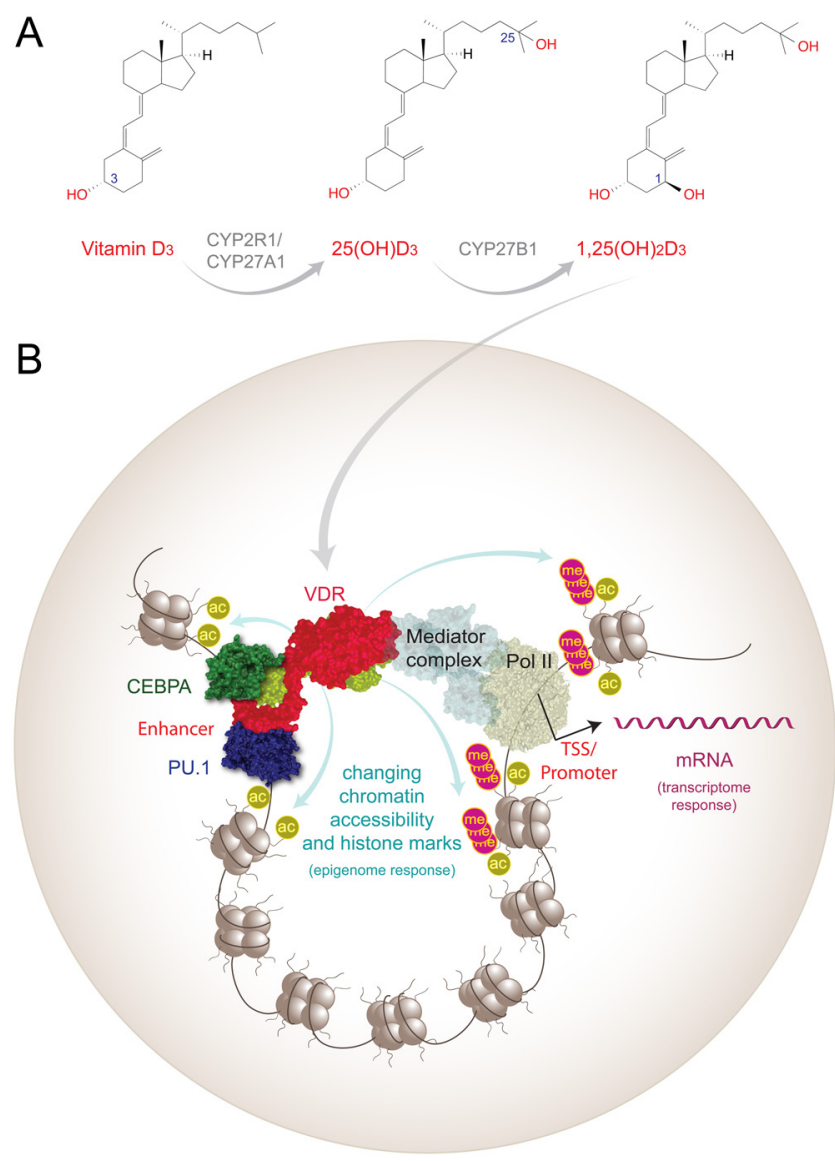

\section{Figure 1}

Vitamin D signaling in the context of chromatin. Via CYP enzyme-driven hydroxylation reactions vitamin $D_{3}$ is converted to 25-hydroxyvitamin $D_{3}$ $\left(25(\mathrm{OH}) \mathrm{D}_{3}\right)$ and $1,25(\mathrm{OH})_{2} \mathrm{D}_{3}(\mathrm{~A})$. The latter vitamin $\mathrm{D}$ metabolite binds with high affinity to VDR (red) bound to thousands of accessible genomic regions (B). VDR binding and placement of histone marks (H3K27ac) at respective enhancer regions as well as changes in chromatin accessibility are supported by pioneer transcription factors, such as PU.1 (dark blue) and CEBPA (green). Looping of VDR-bound enhancers to TSS regions leads to changes to histone marks at promoters (H3K4me3 and H3K27ac) and the activation RNA polymerase II. This finally leads to mRNA transcription of respective vitamin $D$ target genes.-

(c) 2020 Society for Endocrinology Published by Bioscientifica Ltd. Printed in Great Britain
org/ENSG00000111424-VDR/tissue), $1,25(\mathrm{OH})_{2} \mathrm{D}_{3}$ is a nuclear hormone that is able to modulate gene expression throughout the whole human body (Sutton \& MacDonald 2003).

In general, the expression of a gene requires that its regulatory regions, such as TSSs (transcription start sites) and transcription factor-binding sites located within accessible chromatin (Haberle \& Stark 2018). Chromatin is a complex of genomic DNA and histone proteins forming nucleosomes, a major purpose of which is to restrict the access of transcription factors to regulatory regions, such as enhancers (Rando \& Chang 2009). The simplest form of an enhancer is a single transcription factor-binding site, while super-enhancers contain multiple single enhancers (Whyte et al. 2013). Well-known markers for active chromatin are acetylated histone $\mathrm{H} 3$ proteins at position lysine 27 (H3K27ac) (Creyghton et al. 2010). Interestingly, within a terminally differentiated cell only some 100,000 genomic regions are accessible, i.e. they can act as enhancers (ENCODE-Project-Consortium 2012).

The genome-wide information included in covalent and structural modifications of chromatin is referred as the epigenome (Rivera \& Ren 2013). Chromatin is the molecular representation of the epigenome on the level of post-translational modifications of histone proteins, DNA methylation and 3D organization, such as TADs (topologically associated domains) (Carlberg \& Molnár 2016). In contrast to the genome, the epigenome is dynamic and can be modulated by environmental signals, such as $1,25(\mathrm{OH})_{2} \mathrm{D}_{3}$. Thus, different attributes of the epigenome, such as histone modifications and the binding of transcription factors, are vitamin D sensitive (Carlberg 2017).

In summary, this review discusses the epigenome- and transcriptome-wide response of vitamin D target tissues in the context of chromatin. We will present regulatory scenarios of vitamin D target genes that are based on the VDR binding to different types of enhancers.

\section{Vitamin D signaling in the context of chromatin}

At present, the most comprehensive set of epigenome- and transcriptome-wide data on the actions of vitamin $\mathrm{D}$ are available from cells of the hematopoietic system (Carlberg 2014). Accordingly, the chromatin model of vitamin D signaling (Fig. 1B) is primarily based on data (Carlberg 2017, 2019) obtained in the human monocytic cell line THP-1, which was derived from the peripheral blood of a 1-year-old human male with acute monocytic leukemia 
(Tsuchiya et al. 1980). The chromatin model describes the sequential process of vitamin D target gene activation, the central event of which is the high-affinity binding of $1,25(\mathrm{OH})_{2} \mathrm{D}_{3}$ to the VDR, when the receptor is located in the nucleus. The VDR cistrome, i.e. the receptor's genome-wide binding pattern, had been determined by the method ChIP-seq (chromatin immunoprecipitation combined with massive parallel sequencing) in a number of human cell culture models, such as GM10855 and GM10861 B lymphocytes (Ramagopalan et al. 2010), LS180 colorectal cancer cells (Meyer et al. 2012), RWPE1 prostate epithelial cells (Fleet et al. 2019), LX2 hepatic stellate cells (Ding et al. 2013) and lipopolysaccharide-polarized THP-1 cells (Tuoresmäki et al. 2014), but most intensively it was studied in undifferentiated THP-1 cells (Heikkinen et al. 2011, Neme et al. 2017). In the presence of ligand, in these in vitro model systems some 5000-20,000 genomic VDRbinding sites had been detected, which represents a 2- to 10 -fold increase compared to cells not stimulated with $1,25(\mathrm{OH})_{2} \mathrm{D}_{3}$.

In THP-1 cells, ChIP-seq detected 11,657 VDR-binding sites (Neme et al. 2017). This largely exceeds the number of primary vitamin $\mathrm{D}$ target genes in the same cell line, i.e. genes that are significantly up- or downregulated within the first $4 \mathrm{~h}$ after ligand stimulation. Interestingly, out of this large pool of VDR loci only 510 are persistent, i.e. they are occupied at all conditions. Nevertheless, the binding of VDR to its persistent sites can change significantly over time after ligand stimulation. Thus, persistent VDR loci are the primary contacts of the genome with $1,25(\mathrm{OH})_{2} \mathrm{D}_{3}$ and in addition coordinate the functional consequences of vitamin D stimulation over time. The machine learning algorithm SOM (self-organizing map) (Kohonen 1995) reduced the number of these persistent loci to 339 sites (Neme et al. 2017). Persistent VDR loci are positioned strategically over the whole human genome, which fits with the pattern of the genomic location of primary vitamin D target genes (Neme et al. 2016b). In addition, there are 2109 transient VDR-binding sites, i.e. loci where the binding of VDR is significantly induced by stimulation with $1,25(\mathrm{OH})_{2} \mathrm{D}_{3}$. Transient VDR sites are not always occupied, but this allows these loci to modulate the response of the epigenome to vitamin D either alone or in coordination with persistent VDR sites, in order to regulate primary vitamin $\mathrm{D}$ target genes. However, the large majority of VDR-binding events (9038 sites) are observed only after a ligand stimulation over $24 \mathrm{~h}$. Thus, the $1,25(\mathrm{OH})_{2} \mathrm{D}_{3}$-stimulated, genome-wide binding of VDR to its preferred loci is the primary epigenome-wide effect of vitamin D.
There are a number of secondary epigenome-wide effects of $1,25(\mathrm{OH})_{2} \mathrm{D}_{3}$ stimulation, such as a significant modulation in the genomic binding of the pioneer factors PU.1 (purine-rich box 1) (Seuter et al. 2017), CEBPA (CCAAT/enhancer-binding protein alpha) (Nurminen et al. 2019) and GABPA (GA-binding protein transcription factor subunit alpha) (Seuter et al. 2018) to vitamin D-responding chromatin regions. Pioneer factors bind rather promiscuously to genomic DNA and interact with a large number of other proteins (Zaret \& Carroll 2011). In the process of monocyte and granulocyte differentiation PU.1 cooperates with VDR (Novershtern et al. 2011). For example, in THP-1 cells PU.1 is present at nearly $2 / 3$ of all VDR-binding sites (Seuter et al. 2017).

TADs are segments of genomic DNA in a size range from $30 \mathrm{~kb}$ to $3 \mathrm{Mb}$ that define at least 2000 functionally independent domains of our genome (Dixon et al. 2012). The anchors of TAD-forming chromatin loops act as insulators and show high conservation between tissues and cell types (Dixon et al. 2015, Vietri Rudan et al. 2015). The transcription factor CTCF (CCCTC-binding factor) binds to TAD anchors and is one of the key proteins organizing the 3D-structure of chromatin (Ong \& Corces 2014). Interestingly, the binding of CTCF to 1300 of its genomic sites ( $5 \%$ of all) is modulated by $1,25(\mathrm{OH})_{2} \mathrm{D}_{3}$ (Neme et al. 2016a). Approximately 600 of these vitamin D-dependent CTCF sites function as TAD anchors. Thus, the $1,25(\mathrm{OH})_{2} \mathrm{D}_{3}$ sensitivity of CTCF binding to TAD anchors implies that also on the level of 3D chromatin organization vitamin $\mathrm{D}$ affects the epigenome.

Importantly, also the accessibility of chromatin, such as determined by the method FAIRE-seq (formaldehydeassisted isolation of regulatory elements sequencing) (Giresi et al. 2007), is significantly affected at some 9000 genomic loci by $1,25(\mathrm{OH})_{2} \mathrm{D}_{3}$ stimulation (3300 loci after $2 \mathrm{~h}, 4500$ sites after $24 \mathrm{~h}$ and 2400 regions after $48 \mathrm{~h}$ only) (Seuter et al. 2016). This observation was confirmed on the level of histone markers. Accordingly, 550 of 22,998 genomic regions with $\mathrm{H} 3 \mathrm{~K} 4 \mathrm{me} 3$ marks, i.e. primarily promoters, and even 2473 of 45,578 regions with H3K27ac modifications, i.e. mainly enhancers, respond significantly to vitamin D stimulation (Nurminen et al. 2018).

The contacts between VDR-bound enhancer regions and the TSS of vitamin D target genes occur primarily within the same TAD, i.e. the borders of a TAD limit the reach of the effects of an activated VDR locus. Thus, a given VDR-binding site can only affect the expression of vitamin $\mathrm{D}$ target genes within the same TAD. For example, in THP-1 cells there are 425 TADs that contain at least one VDR-binding site and one vitamin D target gene 
(Neme et al. 2016b, 2017). Machine learning algorithms, such as K-means, random forests and SOM, were used for the analysis and implementation of time-dependent data on accessible chromatin and mRNA expression. This approach suggested that the relative amounts of persistent and transient VDR-binding sites are the main attribute for describing the regulatory scenario of a given gene within its TAD (Carlberg \& Neme 2019). For example, TADs comprising vitamin D target genes, which are important for immune function, are primarily regulated by transient VDR sites, i.e. by genomic loci that respond in an 'on/off' modus. In the following, we will present a new analysis relating the occurrence of persistent and transient VDR sites within super-enhancers to the regulation of primary upregulated vitamin D target genes.

Taken together, the chromatin model of vitamin $\mathrm{D}$ signaling (Fig. 1B) suggests that $1,25(\mathrm{OH})_{2} \mathrm{D}_{3}$ binds specifically to VDR molecules, which in a spatio-temporal order settle down on thousands of genomic loci. The contact of VDR with enhancers is supported by pioneer factors at these loci leading to an increase in chromatin accessibility as well as in changes in the marking of histones, i.e. in chromatin activity. VDR-activated enhancers then loop to TSS regions, where RNA polymerase II is stimulated to increase mRNA production. In its present version the model can explain the regulation of primary vitamin $\mathrm{D}$ target genes. In contrast, secondary target genes do not directly require VDR as a central regulator, but may be controlled by a transcription factor, such as BCL6, NFE2, POU4F2 and ELF4 (Nurminen et al. 2015), or a chromatin modifier, such as the lysine demethylase KDM6B (Pereira et al. 2011) or the chromatin remodeler BRD7 (Wei et al. 2018), which themselves are primary vitamin $\mathrm{D}$ target genes.

\section{Transcriptome-wide responses to vitamin D}

The most comprehensive description of the vitamin D-modulated transcriptome, as determined by RNA-seq (RNA sequencing) (Wang et al. 2009), had been performed with THP-1 cells that were stimulated for 2.5, 4 and $24 \mathrm{~h}$ with $1,25(\mathrm{OH})_{2} \mathrm{D}_{3}$ (GSE69284, www.ncbi. nlm.nih.gov/geo). Initially this dataset was aligned to the reference genome (hg19, representing in total 23,487 genes) using the algorithm Bowtie (Langmead et al. 2009). Statistics for differential expression applying the algorithm Cuffdiff (Trapnell et al. 2012) indicated 1284 vitamin D target genes (Seuter et al. 2016). A re-analysis (Neme et al. 2017) of this dataset used STAR alignment (Dobin et al. 2013) for mapping the sequence reads to the genome and the algorithm DESeq2 (Love et al. 2014) for calculating differential expression. This approach even suggested 3650 target genes, i.e. one in four expressed genes, which is an unrealistically high number, indicating a large number of false positives due to weakly regulated genes. Therefore, SOM analysis was performed with the restriction that the average change in gene expression should be at least 2 . This resulted in a list of 587 genes, all of which were vitamin D responsive after $24 \mathrm{~h}$ stimulation (Neme et al. 2017). Interestingly, 311 of these 587 genes (53\%) are primary vitamin D targets, only 12 of which are downregulated.

In the past, lists of differentially expressed genes were filtered either by the highest fold change or lowest $P$ value (Palmer et al. 2003, Heikkinen et al. 2011, Verway et al. 2013). However, highly expressed genes, which are statistically significantly up- or downregulated but do not show very impressive inducibility (fold change) are often overlooked by the traditional approach. Moreover, most gene filtering approaches are quite sensitive to threshold settings. We demonstrate this with the new filtering of the THP-1 time course experiments of Seuter et al. (2016) as an example. In order to include very low expressed but highly induced genes, such as CYP24A1, we defined a gene as 'expressed' when its basal expression times the fold change $24 \mathrm{~h}$ after $1,25(\mathrm{OH})_{2} \mathrm{D}_{3}$ stimulation exceeded the value 10 . This condition applied to 14,011 genes, 3803 of which showed at least at one of the three stimulation time points a significant $(P<0.05)$ change in expression (Fig. 2A). Thus, compared with the first re-analysis of Neme et al. (2017) this less restricted condition increased the number of possible target genes even by 153 candidates. In order to work with a more condensed set of vitamin D genes, we focused on the 100 vitamin D target genes with highest basal activity in combination with the top 100 lists concerning fold change (highest) and $P$ value (lowest) (Fig. 2B). Due to overlaps within the lists of fold change and $P$ value, this led to a total of 264 genes (Supplementary Table 1, see section on supplementary materials given at the end of this article). Only 119 of these 264 genes (45\%) are primary vitamin D targets, six $(5 \%)$ of which are downregulated (Supplementary Table 1). Moreover, only to $11 \%$ of the top 100 genes concerning highest basal activity are primary vitamin $\mathrm{D}$ targets, while this applies to $57 \%$ and even $86 \%$ of the top 100 lists concerning fold change and $P$ value, respectively (Fig. 2C). For comparison, 1.4, 4.3 and $10.2 \%$ of the 587 vitamin D target genes identified after $2.5,4$ and $24 \mathrm{~h}$ after onset of $1,25(\mathrm{OH})_{2} \mathrm{D}_{3}$ stimulation, respectively, are downregulated (Neme et al. 2017).

In summary, the gene filtering approach used here as an alternative example (i.e. the restriction to the top 100 
A

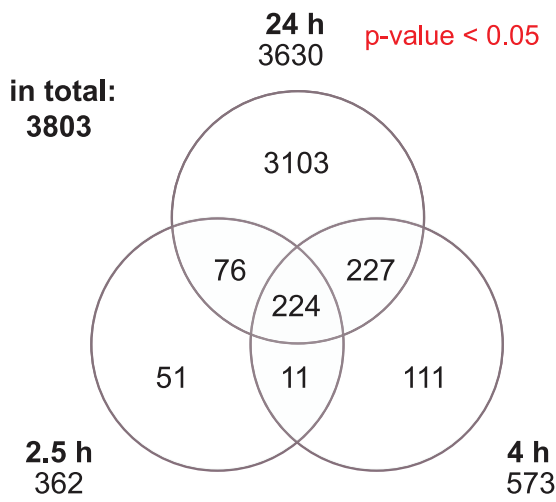

top 100 basal activity top 100 fold change top $100 \mathrm{p}$-value

B

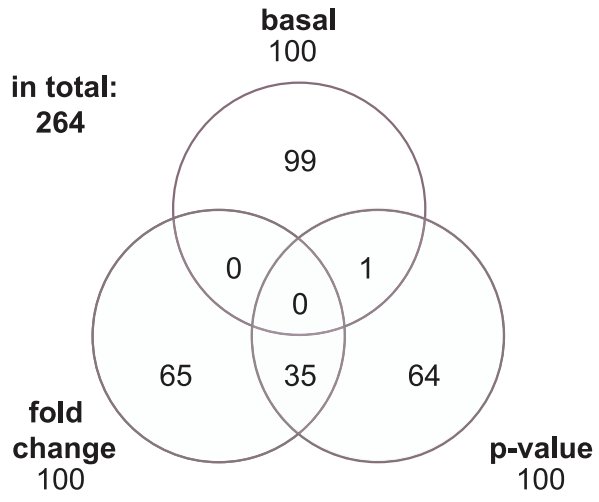

C

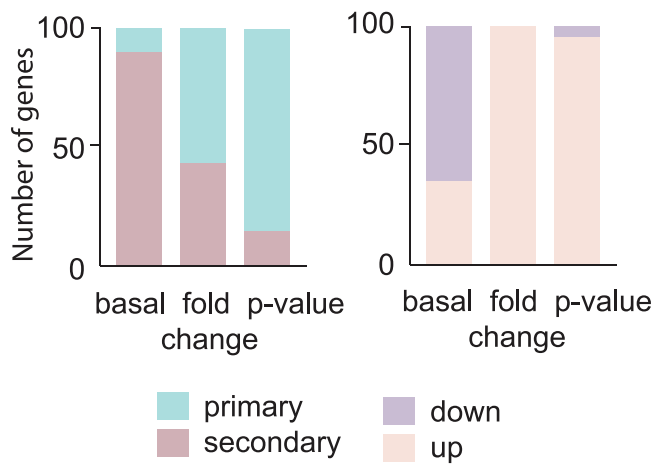

Figure 2

Vitamin D-triggered transcriptome. Venn diagrams were used for displaying different analyses of RNA-seq datasets obtained from THP-1 cells treated in three biological repeats for 2.5, 4 and $24 \mathrm{~h}$ with $10 \mathrm{nM}$ $1,25(\mathrm{OH})_{2} \mathrm{D}_{3}$ in reference to solvent (final concentration $0.1 \%$ ethanol)treated cells (Seuter et al. 2016). Raw data were analyzed using STAR alignment and DESeq2 statistics and provided 3803 significantly $(P<0.05)$ vitamin D-responsive genes (A). An alternative gene filtering approach is the restriction to the top 100 target genes concerning highest basal expression (i.e. absolute expression after solvent treatment), inducibility (highest fold change) and significance (lowest $P$ value), respectively, leading to in total 264 genes (B). Based on the data assembly of Supplementary Table 1, the number of primary and secondary target genes as well as of down- and up-regulated genes is indicated (C). Genes were considered as primary vitamin $D$ targets when their expression changed significantly $(P<0.05)$ within $4 \mathrm{~h}$ after ligand treatment. (c) 2020 Society for Endocrinology Published by Bioscientifica Ltd. Printed in Great Britain genes of each basal expression, fold change and $P$ value) highlights 99 genes as possibly functionally important vitamin $\mathrm{D}$ targets that have not been considered before. Interestingly, the vast majority of these genes are downregulated secondary vitamin $\mathrm{D}$ target genes, which is in clear contrast to genes defined by highest inducibility (i.e. fold change) or sensitivity (i.e. $P$ value).

\section{Regulation of primary vitamin D target genes}

The chromatin model of vitamin D signaling outlines the regulation of induced primary vitamin D target genes. In contrast, there is neither a general model for secondary target gene regulation nor an explanation, how vitamin D target genes are downregulated. Both secondary and downregulated genes have individual mechanisms of regulation that cannot be generalized (Bourdeau et al. 2008). Thus, we will restrict the discussion of gene regulatory scenarios to the 113 primary upregulated target genes (shaded green in Supplementary Table 1).

Top ranking in the list of vitamin D targets with highest basal expression is the $S R G N$ (serglycin) gene, which encodes for a unique intracellular proteoglycan secreted by hematopoietic and endothelial cells (Iozzo \& Schaefer 2015). The IGV (Integrative Genomics Viewer) browser (Thorvaldsdottir et al. 2013) was used for displaying data obtained in THP-1 cells, which had been stimulated for $24 \mathrm{~h}$ with $1,25(\mathrm{OH})_{2} \mathrm{D}_{3}$ or solvent (EtOH). These are ChIPseq data for VDR (Neme et al. 2017), the histone markers H3K27ac and H3K4me3 (Nurminen et al. 2018) and the pioneer factors PU.1 (Seuter et al. 2017) and CEBPA (Nurminen et al. 2019) as well as FAIRE-seq data (Seuter et al. 2016) (Fig. 3). We define vitamin D-driven superenhancers as genomic regions of maximal $20 \mathrm{~kb}$ in size that comprise a cluster of at least three VDR binding loci, one of which should be either a persistent or transient VDR site. The $S R G N$ gene is driven by a super-enhancer that spans over $20 \mathrm{~kb}$ (11-31 kb upstream of the TSS) and contains five VDR-binding loci (one prominent persistent (P) site and four weaker sites that occur only after 24-h stimulation (24)) (Fig. 3A). Interestingly, the five VDR loci are associated with vitamin D-dependent chromatin opening. However, at the TSS regions no VDR binding was detected. This is most likely due to the moderated upregulation of the gene (fold change 1.7), in the context of which enhancer-TSS looping events were not frequent enough, in order to cross-link during ChIP-seq experiments sufficient amounts of the receptor to the TSS.

The gene CD14 (cluster of differentiation 14), which encodes for a Toll-like receptor co-receptor (Zhang et al. 
A

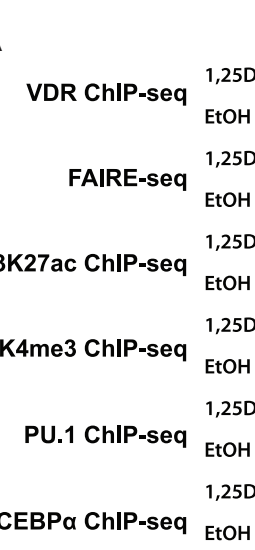$$
\text { CEBPa ChIP-seq }
$$

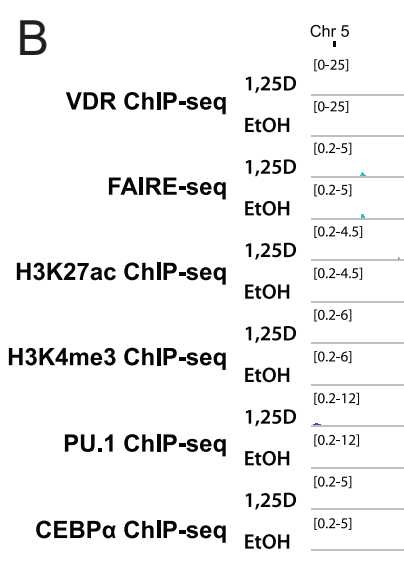

(24) (24) (24) (24)
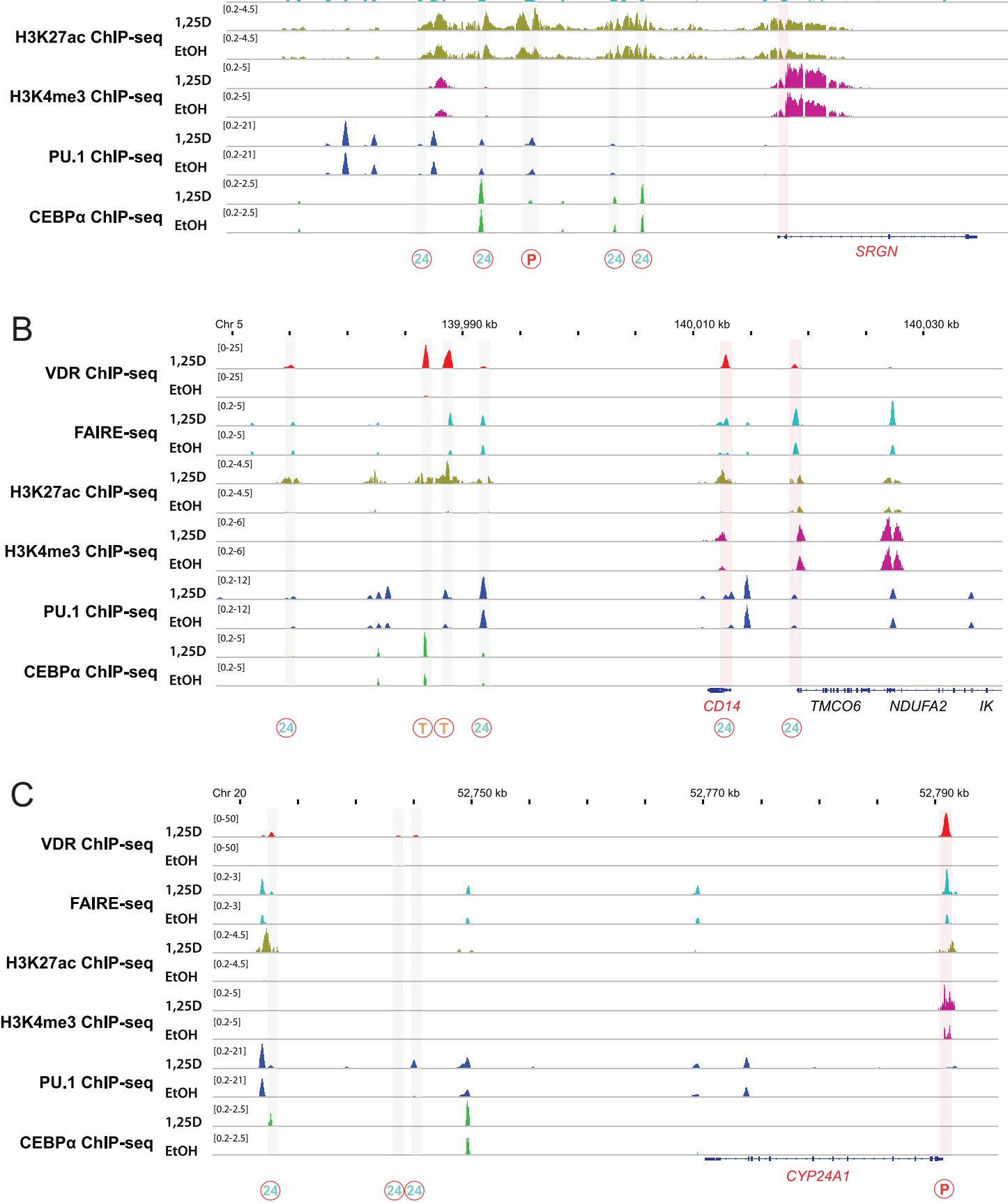

Figure 3

Epigenomic profiles of vitamin D target genes. The IGV browser was used to display the epigenomic profiles at enhancer and TSS regions of the genes SRGN (serglycin, A), CD14 (cluster of differentiation 14, B) and CYP24A1 (cytochrome P450 family 24 subfamily A member 1, C). The peak tracks display merged data from three biological repeats of ChIP-seq experiments with antibodies against VDR (red) (Neme et al. 2017), H3K27ac (light brown) (Nurminen et al. 2018), H3K4me3 (purple) (Nurminen et al. 2018), PU.1 (dark blue) (Seuter et al. 2017) and CEBPA (green) (Nurminen et al. 2019) as well as FAIRE-seq data (light blue) (Seuter et al. 2016) obtained in THP-1 cells that were treated for $24 \mathrm{~h}$ with $1,25(\mathrm{OH})_{2} \mathrm{D}_{3}(1,25 \mathrm{D})$ or vehicle (EtOH). The gene structures are shown in blue and vitamin D target genes are indicated in red. VDR binding sites ( $\mathrm{P}$ (persistent), T (transient) and 24 ( $24 \mathrm{~h}$ only)) at enhancer regions are shaded in gray, while TSS regions are highlighted with a purple shade. 
1994), is the most significantly regulated vitamin D target, i.e. it is top ranking in the p-value list. CD14 is another example of a gene being regulated by a super-enhancer. This VDR cluster region is shorter and only spans over 6 $\mathrm{kb}$ (21-27 kb downstream of the TSS). It contains three VDR binding loci (two transient (T) sites and one '24' site) (Fig. 3B). Moreover, the gene is strongly induced (fold change 83.9) so that VDR can also be detected on the TSS region of CD14 and the neighboring gene TMCO6 (transmembrane and coiled-coil domains 6), although only after $24-\mathrm{h} 1,25(\mathrm{OH})_{2} \mathrm{D}_{3}$ stimulation.

The most induced vitamin D target gene is CYP24A1 (cytochrome P450 family 24 subfamily A member 1), which encodes for a mitochondrial monooxygenase specialized on the degradation of $1,25(\mathrm{OH})_{2} \mathrm{D}_{3}$ (Kerry et al. 1996). Single gene ChIP-qPCR studies had identified a strong VDR binding enhancer only 300 bp upstream of the gene's TSS (Väisänen et al. 2005) and a cluster of additional VDR loci 50-69 kb downstream of the TSS (Meyer et al. 2010). Genome-wide ChIP-seq studies confirmed these VDRbinding sites (Fig. 3C), although the strong persistent VDR site close to TSS cannot be distinguished from TSS occupancy. Similarly, 29 other primary vitamin D target genes are driven by enhancers carrying either a persistent or a transient VDR site close (within $2 \mathrm{~kb}$ ) to their TSS region (Supplementary Table 1). The three VDR-binding sites ('24') downstream of the CYP24A1 gene represent individual weaker enhancers but do not form a superenhancer. Thus, the most likely scenario for CYP24A1 regulation by vitamin $\mathrm{D}$ is the prominent persistent VDR site close to the TSS. This scenario applies to 50 primary upregulated vitamin D target genes.

Taken together, primary upregulated vitamin D target genes are regulated via an enhancer carrying at least one prominent VDR-binding site (persistent or transient) that is located within the same TAD (Carlberg \& Neme 2019, Nurminen et al. 2019). However, the gene regulatory scenarios differ in detail, such as the linear distance between the enhancer and the target gene's TSS as well as in the number of VDR-binding sites per enhancer. The majority of primary upregulated vitamin $\mathrm{D}$ target genes are driven by super-enhancers and will be discussed below in more detail.

\section{Impact of super-enhancers on vitamin $D$ signaling}

In their classical definition, super-enhancers contain binding sites for different types of transcription factors
(Whyte et al. 2013). Since transcription factors are activated by a multitude of different signal transduction pathways, a super-enhancer is able to respond to a number of different signals and serves as their integrator (Hnisz et al. 2017). However, in the context of vitamin D signaling we focus on super-enhancers that carry three or more VDR-binding sites. This concept was first reported for the vitamin D response of the TNFSF11 (TNF superfamily member 11) gene in mouse osteoblastic cells (Kim et al. 2007). We assume that such super-enhancers mediate an enhanced response to vitamin D. For this purpose, we inspected manually each of the 113 primary upregulated vitamin D target genes in THP-1 cells (Supplementary Table 1) for its VDR-binding profile at enhancer regions in a distance of 1 $\mathrm{Mb}$ (for a few genes even further) to its TSS. Interestingly, 29 genes $(25.7 \%$ of all $)$ have a prominent vitamin D response element (11 persistent and 18 transient VDRbinding sites) within $2 \mathrm{~kb}$ of their TSS (Fig. 4). Some of these, such as the one of the CYP24A1 gene (Fig. 3C), have already been identified by single-gene studies during the past 30 years (Pike 1991, Haussler et al. 1997, Carlberg \& Polly 1998).

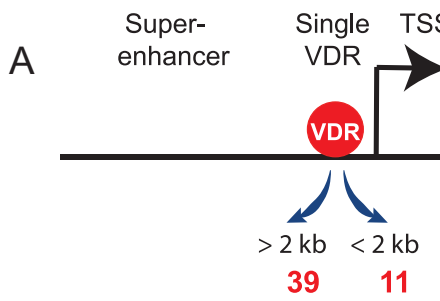

B

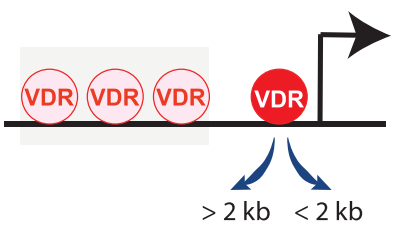

129

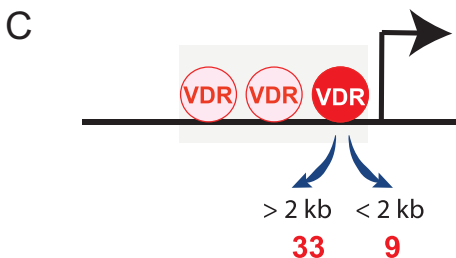

Figure 4

Regulatory scenarios of 113 primary vitamin $D$ target genes. Less than half of the primary vitamin $D$ target genes are regulated by single strong VDR sites close $(<2 \mathrm{~kb})$ or distant $(>2 \mathrm{~kb})$ from their TSS (A). The majority of target genes are associated with VDR clusters forming super-enhancers that are either more distant from the TSS than the single strong VDR sites (B) or comprise the latter site (C). 
Fifty of the 113 primary upregulated genes (44.2\%) do not contain a super-enhancer in a distance of $1 \mathrm{Mb}$ from their TSS, i.e. they are driven by a single vitamin D response element (Fig. 4A). Eleven of these single strong VDR-binding sites are located within the TSS region. In total, 63 of the 113 genes (55.8\%) carry a super-enhancer in a distance of up to $955 \mathrm{~kb}$ from the TSS. Interestingly, 21 of the 63 genes with a super-enhancer have a prominent single vitamin D response element closer to their TSS than the VDR cluster (Fig. 4B). For these 21 genes the single vitamin $\mathrm{D}$ response element may be the more prominent regulator of the gene's expression than the VDR cluster. Nine of these 21 genes carry their single strong VDRbinding site even within $2 \mathrm{~kb}$ of the gene's TSS. In contrast, for 42 of the 63 genes with a VDR cluster the prominent single VDR site is part of a super-enhancer, nine of which comprise the TSS region (Fig. 4C).

Vitamin D-driven super-enhancers contain VDRbinding sites, which were classified as persistent (P), transient (T) and ' $24 \mathrm{~h}$ only' (24) (Neme et al. 2017). For example, the constellation T-24-24, such as observed for the TSPAN18 (tetraspanin 18) gene (Fig. 5C), is found in 26 of the 63 VDR clusters followed by 11 representatives of the P-24-24 configuration, as found for the SRGN gene (Fig. 5A). Other super-enhancer constellations are P-T-24 (8-times), P-T-T (5-times), T-T24 (5-times, as exemplified for the CD14 gene (Fig. 5B)), T-T (4-times), T-T-T (3-times) and P-T (once). All superenhancer constellations (summarized in Supplementary Table 1) are based on a manual inspection of vitamin D target genes using the IGV browser displaying genomewide data as described in Fig. 3 (including datafiles of the respective original publications) as well as the VDRbinding site classification of Neme et al. (2017). We do not count the 13 examples of VDR clusters in a 24-24-24 configuration, such as observed for the CYP24A1 gene (Fig. 3C), as super-enhancers, since these VDR sites most likely have far lower impact than the strong single VDR sites.

The rather low number of genes with VDR clusters (63) did not allow the detection of statistically significant correlations between super-enhancer correlations and the functional profile of primary up-regulated vitamin D target genes. However, there is a tendency that genes that are strongly up-regulated, i.e. genes of high significance (Fig. 5B) and/or high inducibility (Fig. 5C), are dominated by clusters containing transient VDR sites. These genes often show low basal expression, so that they are highly sensitive to transcriptional 'noise', i.e. random fluctuations in gene transcription (Kellogg \& Tay 2015). In contrast,
$A$

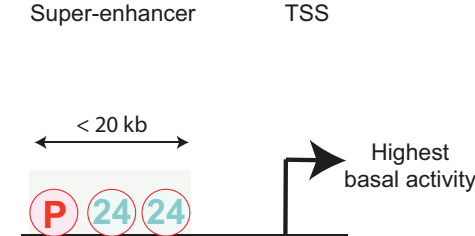

B

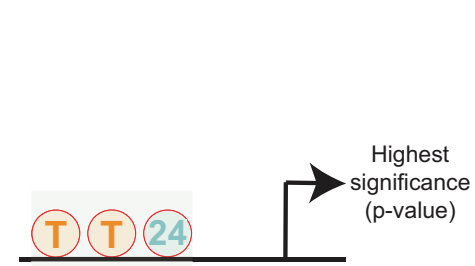

C
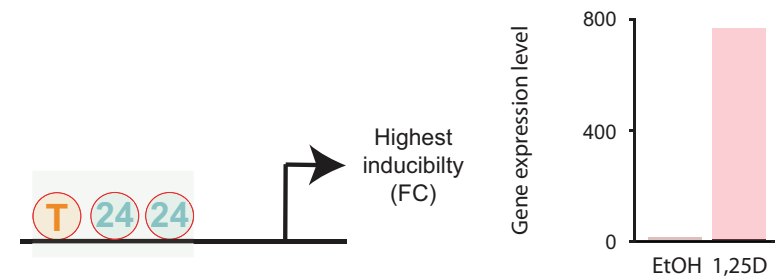

Figure 5

Classification of vitamin $D$ target genes. Based on data assembled in Supplementary Table 1 primary vitamin $D$ target genes can be classified by highest basal activity, inducibility (fold change) and significance ( $P$ value) (left). The expression of the genes SRGN (serglycin, A), CD14 (cluster of differentiation 14, B) and TSPAN18 (tetraspanin 18, C) are used as examples. Representative VDR-binding patterns (P (persistent), T (transient) and 24 (24 h only)) to super-enhancers are related to these three classes of vitamin $D$ target genes (right) and are based on Seuter et al. (2016). 1,25D =1,25(OH) $\mathrm{D}_{3}$.

genes with high basal activity show only minor variations, i.e. they provide more stable results (Fig. 5C). For these genes a regulation via VDR clusters with persistent sites is more appropriate.

In summary, there are three main gene regulatory scenarios for vitamin $\mathrm{D}$ target genes: single strong VDR sites alone as well as in overlap or distance to a superenhancer. There are different types of vitamin D-driven super-enhancers, but their correlation with gene function could not yet be established.

\section{Functional profile of vitamin D target genes}

A central question of the transcriptome-wide analysis of vitamin $\mathrm{D}$ target genes is, how their differential regulation after $1,25(\mathrm{OH})_{2} \mathrm{D}_{3}$ stimulation translates into physiological functions of the investigated cell type or tissue. Gene ontology analysis offers the statistically significant overrepresentation of vitamin D target genes in biological processes. Using the webtool Enrichr (Chen et al. 2013) (https://amp.pharm.mssm.edu/Enrichr) for 
the transcriptome of THP- 1 cells demonstrated that on the basis of the 3803 genes of the raw analysis (Fig. 2A) suggests that the prime function of vitamin $\mathrm{D}$ is energy metabolism, such as 'mitochondrial ATP synthesis coupled electron transport', the 587 SOM filtered genes (Neme et al. 2017) have a major role in signal transduction, such as 'phosphatidylinositol 3-kinase signaling', while the 264 genes based of the three top 100 lists (Fig. 2C) confirmed the expected function of monocytes. The top processes, such as 'neutrophil activation', 'neutrophil mediated immunity', 'neutrophil degranulation' and 'positive regulation of viral entry into host cell' relate to innate immunity, while 'cellular response to lipid', 'regulation of alcohol biosynthetic process', 'cellular response to oxygen-containing compound', 'regulation of cholesterol biosynthetic process' and 'regulation of steroid biosynthetic process' indicate functions in the context of metabolism (Table 1). This fits with the immunometabolism concept (Vanherwegen et al. 2017, Munoz Garcia et al. 2018), which was suggested as main

Table 1 Gene ontology analysis.

\begin{tabular}{|c|c|c|c|}
\hline & Gene ontology term & Adjusted $P$ value & Overlap \\
\hline \multirow[t]{10}{*}{$\begin{array}{l}\text { Top } 100 \text { filtered list } \\
\text { (264 genes) }\end{array}$} & $\begin{array}{l}\text { Neutrophil activation involved in immune response } \\
\text { (GO:0002283) }\end{array}$ & $1,67 \mathrm{E}-04$ & $23 / 484$ \\
\hline & Neutrophil mediated immunity (GO:0002446) & $1,85 \mathrm{E}-04$ & $24 / 488$ \\
\hline & Cellular response to lipid (GO:0071396) & $2,00 \mathrm{E}-04$ & $14 / 179$ \\
\hline & Neutrophil degranulation (GO:0043312) & $2,88 \mathrm{E}-04$ & $23 / 480$ \\
\hline & Regulation of alcohol biosynthetic process (GO:1902930) & $3,23 \mathrm{E}-04$ & $7 / 35$ \\
\hline & $\begin{array}{l}\text { Cellular response to oxygen-containing compound } \\
\text { (GO:1901701) }\end{array}$ & $7,14 \mathrm{E}-04$ & $16 / 275$ \\
\hline & Regulation of cholesterol biosynthetic process (GO:0045540) & $7,20 \mathrm{E}-04$ & $7 / 41$ \\
\hline & Regulation of cholesterol metabolic process (GO:0090181) & $7,48 \mathrm{E}-04$ & $7 / 42$ \\
\hline & Positive regulation of viral entry into host cell (GO:0046598) & 0,001016823 & $4 / 8$ \\
\hline & Regulation of steroid biosynthetic process (GO:0050810) & 0,00108109 & $7 / 45$ \\
\hline \multirow[t]{10}{*}{$\begin{array}{l}\text { SOM-filtered list } \\
\text { (587 genes) }\end{array}$} & $\begin{array}{l}\text { Regulation of phosphatidylinositol 3-kinase signaling } \\
\text { (GO:0014066) }\end{array}$ & 0,003231095 & $13 / 81$ \\
\hline & $\begin{array}{l}\text { Positive regulation of phospholipid metabolic process } \\
\text { (GO:1903727) }\end{array}$ & 0,003333861 & $8 / 29$ \\
\hline & Regulation of cell migration (GO:0030334) & 0,003351463 & $26 / 317$ \\
\hline & $\begin{array}{l}\text { Positive regulation of phosphatidylinositol 3-kinase } \\
\text { signaling (GO:0014068) }\end{array}$ & 0,003352442 & $10 / 54$ \\
\hline & $\begin{array}{l}\text { Regulation of phosphatidylinositol 3-kinase activity } \\
\text { (GO:0043551) }\end{array}$ & 0,004129987 & $8 / 34$ \\
\hline & Podosome assembly (GO:0071800) & 0,004161661 & $5 / 9$ \\
\hline & $\begin{array}{l}\text { Positive regulation of phosphatidylinositol 3-kinase activity } \\
\text { (GO:0043552) }\end{array}$ & 0,005339282 & $7 / 26$ \\
\hline & Positive regulation of lipid kinase activity (GO:0090218) & 0,007103159 & $7 / 28$ \\
\hline & Regulation of platelet activation (GO:0010543) & 0,007781412 & $6 / 19$ \\
\hline & $\begin{array}{l}\text { Positive regulation of intracellular signal transduction } \\
\text { (GO:1902533) }\end{array}$ & 0,007862047 & $32 / 480$ \\
\hline \multirow[t]{10}{*}{$\begin{array}{l}\text { Raw analysis list } \\
\text { (3803 genes) }\end{array}$} & $\begin{array}{l}\text { Mitochondrial ATP synthesis coupled electron transport } \\
\text { (GO:0042775) }\end{array}$ & $2,59 \mathrm{E}-15$ & $54 / 86$ \\
\hline & Respiratory electron transport chain (GO:0022904) & $1,96 \mathrm{E}-14$ & $56 / 95$ \\
\hline & Neutrophil degranulation (GO:0043312) & $2,94 \mathrm{E}-08$ & $151 / 480$ \\
\hline & $\begin{array}{l}\text { Neutrophil activation involved in immune response } \\
\text { (GO:0002283) }\end{array}$ & $3,64 \mathrm{E}-08$ & $152 / 484$ \\
\hline & $\begin{array}{l}\text { Mitochondrial respiratory chain complex I assembly } \\
\text { (GO:0032981) }\end{array}$ & $4,40 \mathrm{E}-08$ & $36 / 65$ \\
\hline & Neutrophil-mediated immunity (GO:0002446) & $4,80 \mathrm{E}-08$ & $153 / 488$ \\
\hline & $\begin{array}{l}\text { Mitochondrial respiratory chain complex I biogenesis } \\
\text { (GO:0097031) }\end{array}$ & $5,03 E-08$ & $36 / 65$ \\
\hline & NADH dehydrogenase complex assembly (GO:0010257) & $5,87 \mathrm{E}-08$ & $36 / 65$ \\
\hline & $\begin{array}{l}\text { Mitochondrial electron transport, NADH to ubiquinone } \\
\text { (GO:0006120) }\end{array}$ & $7,87 \mathrm{E}-08$ & $29 / 47$ \\
\hline & Mitochondrial transport (GO:0006839) & $2,84 \mathrm{E}-06$ & $55 / 136$ \\
\hline
\end{tabular}

Lists of vitamin D target genes (Fig. 2) were analyzed using the web-tool Enrichr for most significant biological processes.

https://jme.bioscientifica.com

https://doi.org/10.1530/JME-19-0246
(C) 2020 Society for Endocrinology Published by Bioscientifica Ltd. Printed in Great Britain 
function of vitamin D-responsive cells of the innate immune system, such as monocytes and their derivatives, dendritic cells and macrophages.

The most prominent locations of the proteins encoded by the 264 vitamin D target genes (Supplementary Table 1) are the plasma membrane $(34.5 \%)$, the nucleus $(22.0 \%)$, the cytosol $(12.5 \%)$, the cytoskeleton $(5.3 \%)$ and the endoplasmatic reticulum (5.3\%). Moreover, $9.8 \%$ of the proteins are primarily secreted. Since proteins with an important role in immunity are primarily found at the plasma membrane or are secreted, this observation confirms the link of proteins encoded by vitamin D target genes in the immune system.

Taken together, the approach of the restricted list of vitamin $\mathrm{D}$ target genes including genes with high basal activity demonstrated its reliability by highlighting functionally important vitamin D target genes involved in immunometabolism.

\section{Conclusion}

In this analytical review, we extended the chromatin model of vitamin D signaling by the concept of VDR clusters. More than half of all primary upregulated vitamin D target genes are regulated by super-enhancers containing strong VDR-binding sites. In this context, we demonstrated that vitamin $\mathrm{D}$ target genes should not only be classified according to their significance and inducibility, but that also the basal expression of the genes should be taken into account. This approach highlighted some 100 genes that previously have been neglected. The inclusion of these genes as well as a focus on the genes with highest significance and inducibility provided a reliable description of the functional response to vitamin D.

The analysis presented here is primarily based on an in vitro model (THP-1 cells), which had been treated with a super-physiological concentration of $1,25(\mathrm{OH})_{2} \mathrm{D}_{3}(10$ $\mathrm{nM}$ ) in a de-lipidized cell culture medium context. Thus, the up to 400-fold inductions of genes, such as CYP24A1, will not be observed under in vivo conditions. Recently, we developed an experimental system, in which human volunteers were treated with a bolus of vitamin $\mathrm{D}_{3}(2000$ $\mu \mathrm{g})$ and changes of gene expression with peripheral blood mononuclear cells (PBMCs), which were isolated before and $24 \mathrm{~h}$ after the bolus, was measured by RNA-seq (Neme et al. 2019). Although far lower fold changes were observed, 702 genes significantly $(P<0.05)$ changed their expression. Interestingly, 181 (25.8\%) of these vitamin D target genes had already been described in THP-1 cells (Seuter et al. 2016). Thus, the here presented extension of the chromatin model of vitamin D signaling will be soon applied for primary human cells, such as PBMCs.

\section{Supplementary materials}

This is linked to the online version of the paper at https://doi.org/10.1530/ JME-19-0246.

\section{Declaration of interest}

The authors declare that there is no conflict of interest that could be perceived as prejudicing the impartiality of this review.

\section{Funding}

This research did not receive any specific grant from any funding agency in the public, commercial or not-for-profit sector.

\section{References}

Bouillon R \& Suda T 2014 Vitamin D: calcium and bone homeostasis during evolution. BoneKEy Reports 3 480. (https://doi.org/10.1038/ bonekey.2013.214)

Bourdeau V, Deschenes J, Laperriere D, Aid M, White JH \& Mader S 2008 Mechanisms of primary and secondary estrogen target gene regulation in breast cancer cells. Nucleic Acids Research 36 76-93. (https://doi.org/10.1093/nar/gkm945)

Carlberg C 2014 Genome-wide (over)view on the actions of vitamin D. Frontiers in Physiology 5 167. (https://doi.org/10.3389/ fphys.2014.00167)

Carlberg C 2017 Molecular endocrinology of vitamin D on the epigenome level. Molecular and Cellular Endocrinology 453 14-21. (https://doi.org/10.1016/j.mce.2017.03.016)

Carlberg C 2019 Vitamin D signaling in the context of innate immunity: focus on human monocytes. Frontiers in Immunology $\mathbf{1 0}$ 2211. (https://doi.org/10.3389/fimmu.2019.02211)

Carlberg C \& Molnár F 2016 The impact of chromatin. In Mechanisms of Gene Regulation, 2nd ed., pp. 17-34. Springer. (https://doi. org/10.1007/978-94-017-7741-4)

Carlberg C \& Neme A 2019 Machine learning approaches infer vitamin D signaling: critical impact of vitamin D receptor binding within topologically associated domains. Journal of Steroid Biochemistry and Molecular Biology 185 103-109. (https://doi. org/10.1016/j.jsbmb.2018.07.015)

Carlberg C \& Polly P 1998 Gene regulation by vitamin $\mathrm{D}_{3}$. Critical Reviews in Eukaryotic Gene Expression 8 19-42. (https://doi. org/10.1615/critreveukargeneexpr.v8.i1.20)

Carmeliet G, Dermauw V \& Bouillon R 2015 Vitamin D signaling in calcium and bone homeostasis: a delicate balance. Best Practice and Research: Clinical Endocrinology and Metabolism 29 621-631. (https:// doi.org/10.1016/j.beem.2015.06.001)

Chen EY, Tan CM, Kou Y, Duan Q, Wang Z, Meirelles GV, Clark NR \& Ma'ayan A 2013 Enrichr: interactive and collaborative HTML5 gene list enrichment analysis tool. BMC Bioinformatics 14 128. (https:// doi.org/10.1186/1471-2105-14-128)

Chun RF, Liu PT, Modlin RL, Adams JS \& Hewison M 2014 Impact of vitamin D on immune function: lessons learned from genome-wide analysis. Frontiers in Physiology 5 151. (https://doi.org/10.3389/ fphys.2014.00151)

Creyghton MP, Cheng AW, Welstead GG, Kooistra T, Carey BW, Steine EJ, Hanna J, Lodato MA, Frampton GM, Sharp PA, et al. 2010 
Histone H3K27ac separates active from poised enhancers and predicts developmental state. PNAS 107 21931-21936. (https://doi. org/10.1073/pnas.1016071107)

Ding N, Yu RT, Subramaniam N, Sherman MH, Wilson C, Rao R, Leblanc M, Coulter S, He M, Scott C, et al. 2013 A vitamin D receptor/SMAD genomic circuit gates hepatic fibrotic response. Cell 153 601-613. (https://doi.org/10.1016/j.cell.2013.03.028)

Dixon JR, Selvaraj S, Yue F, Kim A, Li Y, Shen Y, Hu M, Liu JS \& Ren B 2012 Topological domains in mammalian genomes identified by analysis of chromatin interactions. Nature 485 376-380. (https://doi org/10.1038/nature11082)

Dixon JR, Jung I, Selvaraj S, Shen Y, Antosiewicz-Bourget JE, Lee AY, Ye Z, Kim A, Rajagopal N, Xie W, et al. 2015 Chromatin architecture reorganization during stem cell differentiation. Nature 518 331-336. (https://doi.org/10.1038/nature14222)

Dobin A, Davis CA, Schlesinger F, Drenkow J, Zaleski C, Jha S, Batut P, Chaisson M \& Gingeras TR 2013 STAR: ultrafast universal RNA-seq aligner. Bioinformatics 29 15-21. (https://doi.org/10.1093/ bioinformatics/bts635)

ENCODE Project Consortium 2012 An integrated encyclopedia of DNA elements in the human genome. Nature 489 57-74. (https://doi. org/10.1038/nature11247)

Fleet JC, Kovalenko PL, Li Y, Smolinski J, Spees C, Yu JG, ThomasAhner JM, Cui M, Neme A, Carlberg C, et al. 2019 Vitamin D signaling suppresses early prostate carcinogenesis in TgAPT121 mice. Cancer Prevention Research 12 343-356. (https://doi.org/10.1158/19406207.CAPR-18-0401)

Giresi PG, Kim J, McDaniell RM, Iyer VR \& Lieb JD 2007 FAIRE (Formaldehyde-Assisted Isolation of Regulatory Elements) isolates active regulatory elements from human chromatin. Genome Research 17 877-885. (https://doi.org/10.1101/gr.5533506)

Haberle V \& Stark A 2018 Eukaryotic core promoters and the functional basis of transcription initiation. Nature Reviews: Molecular Cell Biology 19 621-637. (https://doi.org/10.1038/s41580-018-00288)

Hanel A \& Carlberg C 2019 Vitamin D and evolution: pharmacologic implications. Biochemistry and Pharmacology 173 113595. (https://doi. org/10.1016/j.bcp.2019.07.024)

Haussler MR, Haussler CA, Jurutka PW, Thompson PD, Hsieh JC, Remus LS, Selznick SH \& Whitfield GK 1997 The vitamin D hormone and its nuclear receptor: molecular actions and disease states. Journal of Endocrinology 154 (Supplement) S57-S73.

Haussler MR, Whitfield GK, Kaneko I, Haussler CA, Hsieh D, Hsieh JC \& Jurutka PW 2013 Molecular mechanisms of vitamin D action. Calcified Tissue International 92 77-98. (https://doi.org/10.1007/ s00223-012-9619-0)

Heikkinen S, Väisänen S, Pehkonen P, Seuter S, Benes V \& Carlberg C 2011 Nuclear hormone $1 \alpha, 25$-dihydroxyvitamin $\mathrm{D}_{3}$ elicits a genomewide shift in the locations of VDR chromatin occupancy. Nucleic Acids Research 39 9181-9193. (https://doi.org/10.1093/nar/gkr654)

Hnisz D, Shrinivas K, Young RA, Chakraborty AK \& Sharp PA 2017 A phase separation model for transcriptional control. Cell 169 13-23. (https://doi.org/10.1016/j.cell.2017.02.007)

Holick MF 2011 Photobiology of vitamin D. In Vitamin D, 3rd ed., pp. 13-22, Academin press. (https://doi.org/10.1016/C2009-1-63406-7)

Iozzo RV \& Schaefer L 2015 Proteoglycan form and function: a comprehensive nomenclature of proteoglycans. Matrix Biology $\mathbf{4 2}$ 11-55. (https://doi.org/10.1016/j.matbio.2015.02.003)

Kellogg RA \& Tay S 2015 Noise facilitates transcriptional control under dynamic inputs. Cell 160 381-392. (https://doi.org/10.1016/j. cell.2015.01.013)

Kerry DM, Dwivedi PP, Hahn CN, Morris HA, Omdahl JL \& May BK 1996 Transcriptional synergism between vitamin D-responsive elements in the rat 25-hydroxyvitamin $\mathrm{D}_{3}$ 24-hydroxylase (CYP) promoter. Journal of Biological Chemistry 271 29715-29721. (https:// doi.org/10.1074/jbc.271.47.29715)
Khanal RC \& Nemere I 2007 The ERp57/GRp58/1,25D3-MARRS receptor: multiple functional roles in diverse cell systems. Current Medicinal Chemistry 14 1087-1093. (https://doi org/10.2174/092986707780362871)

Kim S, Yamazaki M, Zella LA, Meyer MB, Fretz JA, Shevde NK \& Pike JW 2007 Multiple enhancer regions located at significant distances upstream of the transcriptional start site mediate RANKL gene expression in response to 1,25-dihydroxyvitamin $\mathrm{D}_{3}$. Journal of Steroid Biochemistry and Molecular Biology 103 430-434. (https://doi. org/10.1016/j.jsbmb.2006.12.020)

Kohonen T 1995 Self-organizing maps. In Springer Series in Information Sciences volume 30, Springer-Verlag: Berlin, German.

Langmead B, Trapnell C, Pop M \& Salzberg SL 2009 Ultrafast and memory-efficient alignment of short DNA sequences to the human genome. Genome Biology 10 R25. (https://doi.org/10.1186/gb-200910-3-r25)

Love MI, Huber W \& Anders S 2014 Moderated estimation of fold change and dispersion for RNA-seq data with DESeq2. Genome Biology 15 550. (https://doi.org/10.1186/s13059-014-0550-8)

Lu M, McComish BJ, Burdon KP, Taylor BV \& Körner H 2019 The association between vitamin $\mathrm{D}$ and multiple sclerosis risk: 1,25(OH)2D3 induces super-enhancers bound by VDR. Frontiers in Immunology 10 488. (https://doi.org/10.3389/ fimmu.2019.00488)

Meyer MB, Goetsch PD \& Pike JW 2010 A downstream intergenic cluster of regulatory enhancers contributes to the induction of CYP24A1 expression by $1 \alpha, 25$-dihydroxyvitamin $\mathrm{D}_{3}$. Journal of Biological Chemistry 285 15599-15610. (https://doi.org/10.1074/jbc. M110.119958)

Meyer MB, Goetsch PD \& Pike JW 2012 VDR/RXR and TCF4/betacatenin cistromes in colonic cells of colorectal tumor origin: impact on c-FOS and c-MYC gene expression. Molecular Endocrinology 26 37-51. (https://doi.org/10.1210/me.2011-1109)

Munoz Garcia A, Kutmon M, Eijssen L, Hewison M, Evelo CT \& Coort SL 2018 Pathway analysis of transcriptomic data shows immunometabolic effects of vitamin D. Journal of Molecular Endocrinology 60 95-108. (https://doi.org/10.1530/JME-17-0186)

Neme A, Seuter S \& Carlberg C 2016a Vitamin D-dependent chromatin association of CTCF in human monocytes. Biochimica and Biophysica Acta 1859 1380-1388. (https://doi.org/10.1016/j. bbagrm.2016.08.008)

Neme A, Nurminen V, Seuter S \& Carlberg C 2016b The vitamin D-dependent transcriptome of human monocytes. Journal of Steroid Biochemistry and Molecular Biology 164 180-187. (https://doi. org/10.1016/j.jsbmb.2015.10.018)

Neme A, Seuter S \& Carlberg C 2017 Selective regulation of biological processes by vitamin $\mathrm{D}$ based on the spatio-temporal cistrome of its receptor. Biochimica et Biophysica Acta: Gene Regulatory Mechanisms 1860 952-961. (https://doi.org/10.1016/j.bbagrm.2017.07.002)

Neme A, Seuter S, Malinen M, Nurmi T, Tuomainen TP, Virtanen JK \& Carlberg C 2019 In vivo transcriptome changes of human white blood cells in response to vitamin D. Journal of Steroid Biochemistry and Molecular Biology 188 71-76. (https://doi.org/10.1016/j. jsbmb.2018.11.019)

Novershtern N, Subramanian A, Lawton LN, Mak RH, Haining WN, McConkey ME, Habib N, Yosef N, Chang CY, Shay T, et al. 2011 Densely interconnected transcriptional circuits control cell states in human hematopoiesis. Cell 144 296-309. (https://doi.org/10.1016/j. cell.2011.01.004

Nurminen V, Neme A, Ryynanen J, Heikkinen S, Seuter S \& Carlberg C 2015 The transcriptional regulator BCL6 participates in the secondary gene regulatory response to vitamin D. Biochimica et Biophysica Acta 1849 300-308. (https://doi.org/10.1016/j. bbagrm.2014.12.001)

Nurminen V, Neme A, Seuter S \& Carlberg C 2018 The impact of the vitamin D-modulated epigenome on VDR target gene regulation. 
Biochimica et Biophysica Acta: Gene Regulatory Mechanisms 1861 697-705. (https://doi.org/10.1016/j.bbagrm.2018.05.006)

Nurminen V, Neme A, Seuter S \& Carlberg C 2019 Modulation of vitamin D signaling by the pioneer factor CEBPA. Biochimica et Biophysica Acta: Gene Regulatory Mechanisms 1862 96-106. (https:// doi.org/10.1016/j.bbagrm.2018.12.004)

Nykjaer A, Dragun D, walther D, Vorum H, Jacobsen C, Herz J, Melsen F, Christensen EI \& Willnow TE 1999 An endocytic pathway essential for renal uptake and activation of the steroid 25-(OH) vitamin D3. Cell 96 507-515. (https://doi.org/10.1016/s0092-8674(00)80655-8)

Ong CT \& Corces VG 2014 CTCF: an architectural protein bridging genome topology and function. Nature Reviews: Genetics 15 234-246. (https://doi.org/10.1038/nrg3663)

Palmer HG, Sanchez-Carbayo M, Ordonez-Moran P, Larriba MJ, CordonCardo C \& Munoz A 2003 Genetic signatures of differentiation induced by $1 \alpha, 25$-dihydroxyvitamin $\mathrm{D}_{3}$ in human colon cancer cells. Cancer Research 63 7799-7806.

Pereira F, Barbachano A, Silva J, Bonilla F, Campbell MJ, Munoz A \& Larriba MJ $2011 \mathrm{KDM6B} / J M J D 3$ histone demethylase is induced by vitamin D and modulates its effects in colon cancer cells. Human Molecular Genetics 20 4655-4665. (https://doi.org/10.1093/hmg/ ddr399)

Pike JW 1991 Vitamin $D_{3}$ receptors: structure and function in transcription. Annual Review of Nutrition 11 189-216. (https://doi. org/10.1146/annurev.nu.11.070191.001201)

Ramagopalan SV, Heger A, Berlanga AJ, Maugeri NJ, Lincoln MR, Burrell A, Handunnetthi L, Handel AE, Disanto G, Orton SM, et al. 2010 A ChIP-seq defined genome-wide map of vitamin D receptor binding: associations with disease and evolution. Genome Research 20 1352-1360. (https://doi.org/10.1101/gr.107920.110)

Rando OJ \& Chang HY 2009 Genome-wide views of chromatin structure. Annual Review of Biochemistry 78 245-271. (https://doi. org/10.1146/annurev.biochem.78.071107.134639)

Rivera CM \& Ren B 2013 Mapping human epigenomes. Cell 155 39-55. (https://doi.org/10.1016/j.cell.2013.09.011)

Seuter S, Neme A \& Carlberg C 2016 Epigenome-wide effects of vitamin $\mathrm{D}$ and their impact on the transcriptome of human monocytes involve CTCF. Nucleic Acids Research 44 4090-4104. (https://doi.org/10.1093/nar/gkv1519)

Seuter S, Neme A \& Carlberg C 2017 Epigenomic PU.1-VDR crosstalk modulates vitamin D signaling. Biochimica et Biophysica Acta: Gene Regulatory Mechanisms 1860 405-415. (https://doi.org/10.1016/j. bbagrm.2017.02.005)

Seuter S, Neme A \& Carlberg C 2018 ETS transcription factor family member GABPA contributes to vitamin D receptor target gene regulation. Journal of Steroid Biochemistry and Molecular Biology 177 46-52. (https://doi.org/10.1016/j.jsbmb.2017.08.006)

Sutton AL \& MacDonald PN 2003 Vitamin D: more than a 'bone-a-fide' hormone. Molecular Endocrinology 17 777-791. (https://doi. org/10.1210/me.2002-0363)

Thorvaldsdottir H, Robinson JT \& Mesirov JP 2013 Integrative Genomics Viewer (IGV): high-performance genomics data visualization and exploration. Briefings in Bioinformatics 14 178-192. (https://doi. org/10.1093/bib/bbs017)

Trapnell C, Roberts A, Goff L, Pertea G, Kim D, Kelley DR, Pimentel H, Salzberg SL, Rinn JL \& Pachter L 2012 Differential gene and transcript expression analysis of RNA-seq experiments with TopHat and Cufflinks. Nature Protocols 7 562-578. (https://doi.org/10.1038/ nprot.2012.016)

Tsuchiya S, Yamabe M, Yamaguchi Y, Kobayashi Y, Konno T \& Tada K 1980 Establishment and characterization of a human acute monocytic leukemia cell line (THP-1). International Journal of Cancer 26 171-176. (https://doi.org/10.1002/ijc.2910260208)

Tuoresmäki P, Väisänen S, Neme A, Heikkinen S \& Carlberg C 2014 Patterns of genome-wide VDR locations. PLOS ONE 9 e96105. (https://doi.org/10.1371/journal.pone.0096105)

Väisänen S, Dunlop TW, Sinkkonen L, Frank C \& Carlberg C 2005 Spatio-temporal activation of chromatin on the human CYP24 gene promoter in the presence of $1 \alpha, 25$-dihydroxyvitamin $\mathrm{D}_{3}$. Journal of Molecular Biology 350 65-77. (https://doi.org/10.1016/j. jmb.2005.04.057)

van de Peppel J \& van Leeuwen JP 2014 Vitamin D and gene networks in human osteoblasts. Frontiers in Physiology 5 137. (https://doi. org/10.3389/fphys.2014.00137)

Vanherwegen AS, Gysemans C \& Mathieu C 2017 Vitamin D endocrinology on the cross-road between immunity and metabolism. Molecular and Cellular Endocrinology 453 52-67. (https:// doi.org/10.1016/j.mce.2017.04.018)

Verway M, Bouttier M, Wang TT, Carrier M, Calderon M, An BS, Devemy E, McIntosh F, Divangahi M, Behr MA, et al. 2013 Vitamin D induces interleukin-1beta expression: paracrine macrophage epithelial signaling controls M. tuberculosis infection. PLoS Pathogens 9 e1003407. (https://doi.org/10.1371/journal. ppat.1003407)

Vietri Rudan M, Barrington C, Henderson S, Ernst C, Odom DT, Tanay A \& Hadjur S 2015 Comparative Hi-C reveals that CTCF underlies evolution of chromosomal domain architecture. Cell Reports $\mathbf{1 0}$ 1297-1309. (https://doi.org/10.1016/j.celrep.2015.02.004)

Wang Z, Gerstein M \& Snyder M 2009 RNA-Seq: a revolutionary tool for transcriptomics. Nature Reviews: Genetics 10 57-63. (https://doi. org/10.1038/nrg2484)

Wei Z, Yoshihara E, He N, Hah N, Fan W, Pinto AFM, Huddy T, Wang Y, Ross B, Estepa G, et al. 2018 Vitamin D switches BAF complexes to protect beta cells. Cell 173 1135.e15-1149.e15. (https://doi. org/10.1016/j.cell.2018.04.013)

Whitfield GK, Dang HT, Schluter SF, Bernstein RM, Bunag T, Manzon LA, Hsieh G, Dominguez CE, Youson JH, Haussler MR, et al. 2003 Cloning of a functional vitamin $\mathrm{D}$ receptor from the lamprey (Petromyzon marinus), an ancient vertebrate lacking a calcified skeleton and teeth. Endocrinology 144 2704-2716. (https://doi. org/10.1210/en.2002-221101)

Whyte WA, Orlando DA, Hnisz D, Abraham BJ, Lin CY, Kagey MH, Rahl PB, Lee TI \& Young RA 2013 Master transcription factors and mediator establish super-enhancers at key cell identity genes. Cell 153 307-319. (https://doi.org/10.1016/j.cell.2013.03.035)

Zaret KS \& Carroll JS 2011 Pioneer transcription factors: establishing competence for gene expression. Genes and Development 25 2227-2241. (https://doi.org/10.1101/gad.176826.111)

Zhang DE, Hetherington CJ, Gonzalez DA, Chen HM \& Tenen DG 1994 Regulation of CD14 expression during monocytic differentiation induced with $1 \alpha, 25$-dihydroxyvitamin $\mathrm{D}_{3}$. Journal of Immunology 153 3276-3284.

Received in final form 18 March 2020

Accepted 31 March 2020

Accepted Manuscript published online 31 March 2020 https://jme.bioscientifica.com

https://doi.org/10.1530/JME-19-0246
(C) 2020 Society for Endocrinology Published by Bioscientifica Ltd. Printed in Great Britain 